\title{
Controlled oxidation of FeCo magnetic nanoparticles to produce faceted FeCo/ferrite nanocomposites for rf heating applications
}

\author{
K. N. Collier, ${ }^{1,2}$ N. J. Jones, ${ }^{1}$ K. J. Miller, ${ }^{1}$ Y. L. Qin, ${ }^{1}$ D. E. Laughlin, ${ }^{1}$ and M. E. McHenry ${ }^{1,2}$ \\ ${ }^{1}$ Department of Materials Science and Engineering, Carnegie Mellon University, Pittsburgh, \\ Pennsylvania 15213, USA \\ ${ }^{2}$ Department of Biomedical Engineering, Carnegie Mellon University, Pittsburgh, Pennsylvania 15213, USA
}

(Presented 11 November 2008; received 12 September 2008; accepted 29 September 2008; published online 19 March 2009)

\begin{abstract}
We report the oxidation products and qualitative rates for polydisperse FeCo magnetic nanoparticles (MNPs) synthesized using an induction plasma torch. X-ray diffraction (XRD) and TEM showed MNPs to have a thin ferrite shell. Nanopowders were isochronally annealed to promote oxidation and XRD was used to follow the evolution of the $\mathrm{FeCo}$ core and the $\mathrm{Fe}_{3} \mathrm{O}_{4}$ and $\mathrm{FeO}$ oxide shells. Isothermal anneals were used to follow oxidation kinetics at 350 and $500{ }^{\circ} \mathrm{C}$. High resolution transmission electron microscopy (HRTEM) revealed faceted morphologies terminated at (100) and (110) FeCo faces with $(110)_{\mathrm{FeCo}} \|(111)_{\text {oxide }}$ and $(100)_{\mathrm{FeCo}} \|(100)_{\text {oxide }}$, and $[010]_{\mathrm{FeC} 0} \|[011]_{\text {oxide }}$ orientation relationships between the FeCo core and oxide shell. We show HRTEM images of MNP chaining and compare the rf heating of samples of aqueous ferrofluids similarly loaded with as synthesized and oxidized MNPs. (c) 2009 American Institute of Physics. [DOI: 10.1063/1.3054376]
\end{abstract}

\section{INTRODUCTION}

We report a systematic study of the oxidation products and rates for plasma torch synthesized FeCo nanoparticles. ${ }^{1}$ FeCo nanoparticles are being studied in applications including radio-frequency (rf) heating for thermoablative cancer therapies $^{2}$ and magnetomechanical response in tissue scaffolds. ${ }^{3}$ This work furthers the understanding of nanostructural evolution and oxidation products in $\mathrm{FeCo} /$ ferrite nanocomposite materials and their influence on applications. ${ }^{4}$

We report the sequence of oxide formation and epitaxial relationships with polyhedral facetted magnetic $\mathrm{FeCo}$ nanoparticles and the role of Néel relaxation in the rf field activated heating of two-phase $\mathrm{FeCo} /$ ferrite MNPs.

$\mathrm{FeCo}$ nanoparticles are unique in forming stable ferrite coatings for which the oxidation kinetics are sluggish at room temperature (RT). If adherent biocompatible oxide shells are engineered and functionalized with surfactants to stabilize aqueous ferrofluids, MNPs can bind to antibodies to promote cell or tissue attachment and efficient point source heating of nanoparticles can be exploited for thermoablative cancer therapies. The oxide coatings provide polar surfaces for attachment of surfactants and protect the high magnetic moment $\mathrm{FeCo}$ core from corrosion. $\mathrm{FeCo} / \mathrm{ferrite}$ nanocomposites have $\mathrm{FeCo}$ cores with (100) and (110) face truncations, in contrast to previously observed (100) and (111) facets in spinel ferrite MNPs. ${ }^{5}$ This offers the possibility of exploring oxidation rates through specific facets, preferential surface attachment of surfactants, and the role of surface crystallography on exchange bias between oxide shells and FeCo cores.

\section{EXPERIMENTAL PROCEDURE}

Polydisperse $\mathrm{Fe}_{50} \mathrm{Co}_{50}$ MNPs were synthesized using a $50 \mathrm{~kW}, 3 \mathrm{MHz}$ rf Tekna induction plasma torch (PT). ${ }^{3} \mathrm{We}$ started with $\mathrm{Fe}_{50} \mathrm{Co}_{50}$ alloy precursor powders produced by gas atomization ${ }^{6}$ and sieved to $<53 \mu \mathrm{m}$. Consistent with previous experience, ${ }^{7}$ the resulting PT FeCo MNPs had a thin adherent $(\mathrm{Fe}, \mathrm{Co})$-ferrite shell. Initial Mössbauer spectroscopy studies indicate that the oxide has Co-rich and Ferich layers. ${ }^{8}$

Structural characterization was carried out by conventional $\mathrm{x}$-ray diffraction (XRD) on powders using a Rigaku powder diffractometer. In order to reveal their crystal structure, a step size of 0.1 seconds was used, a voltage of $35 \mathrm{keV}$, a range of $25-105^{\circ} 2 \theta$ using a $\mathrm{Cu}$ tube with $K \alpha$ radiation. A Scherrer analysis was performed on these powders and indicated an average particle size of $35 \mathrm{~nm}$ (by volume weighting).

A more direct tool for determining particle size is the transmission electron microscope (TEM). Particle size distributions for the PT synthesized nanoparticles were determined using a JEOL 2000EX TEM. The sizes of the particles were fit to a log-normal distribution with a geometric mean of $19.7 \mathrm{~nm}$ and a standard deviation of $8.5 \mathrm{~nm}$. These measurements reinforce observations ${ }^{9}$ that different techniques yield different values depending on the weighting scheme. High resolution transmission electron microscopy (HRTEM) was performed on a Tecnai F20 TEM to create a threedimensional (3D) morphology of the nanoparticles.

Isochronal oxidation studies were performed between 100 and $1000{ }^{\circ} \mathrm{C}$ for $2 \mathrm{~h}$. The powder samples were then characterized by conventional XRD. Isothermal kinetics of oxidation were studied at 350 and $500{ }^{\circ} \mathrm{C} .1-2 \mathrm{~g}$ samples of the as-PT synthesized powders were heated for 15, 30, 60, 180,360 , and $1440 \mathrm{~min}$. XRD results of the kinetics of oxidation are not discussed here.

dc magnetic properties were studied using a Lakeshore vibrating sample magnetometer (VSM) equipped with a furnace that can operate to $1300 \mathrm{~K}$. Heating of the MNPs in ferrofluids was performed using an AMERITHERM Hotshot rf power supply. This has a $280 \mathrm{kHz}$ maximum power supply operated at $100 \mathrm{~A}$ through a three-turn coil. Heating rates of 


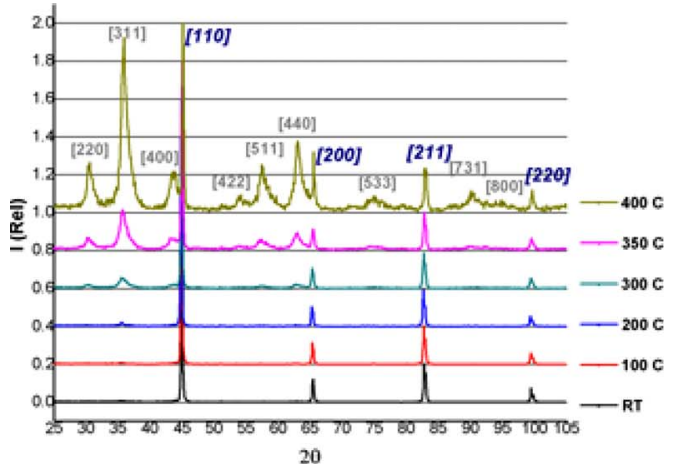

(a)

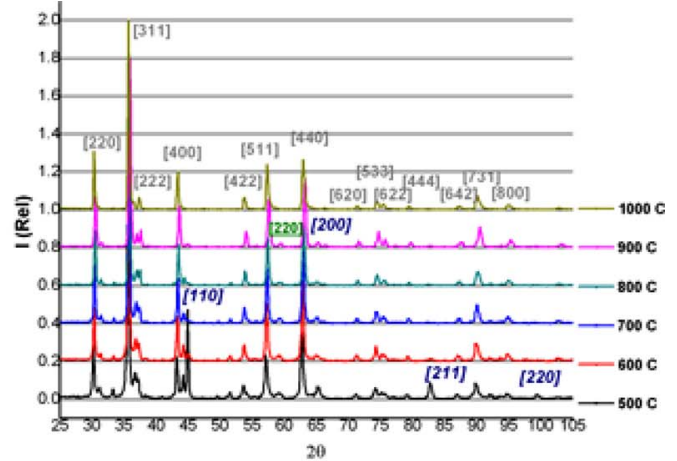

(b)

FIG. 1. (Color online) XRD patterns of FeCo nanoparticles showing oxidation between (a) RT and $400{ }^{\circ} \mathrm{C}$ and (b) 500 and $1000{ }^{\circ} \mathrm{C}$ for $2 \mathrm{~h}$. Dark labels show $\mathrm{FeCo}$ peaks, light labels show $\mathrm{Fe}_{3} \mathrm{O}_{4}$ peaks, and the underlined [220] label shows an $\mathrm{FeO}$ peak.

aqueous ferrofluids with as-PT synthesized FeCo and FeCo oxidized for $2 \mathrm{~h}$ at 350 and $600{ }^{\circ} \mathrm{C}$ were observed. Ferrofluids of $10 \mathrm{wt} \% \mathrm{FeCo}$ functionalized in $2 \mathrm{mM}$ polyethylene oxide (PEO) surfactant solution were heated in the rf coil at 100 A from room temperature. Ferrofluids containing equivalent magnetization of $\mathrm{FeCo}$ were also heated by this process. Concentrations of equivalent magnetization ferrofluids were $9.1 \mathrm{wt} \%$ of as-PT synthesized powder, $10 \mathrm{wt} \%$ of powder oxidized for $2 \mathrm{~h}$ at $350{ }^{\circ} \mathrm{C}$, and $18.3 \mathrm{wt} \%$ of powder oxidized for $2 \mathrm{~h}$ at $600{ }^{\circ} \mathrm{C}$. A Luxtron optical fiber thermometer was used for temperature measurement with data collected every $2 \mathrm{~s}$.

\section{RESULTS AND DISCUSSION}

The measured XRD patterns for varying temperatures are shown in Figs. 1(a) and 1(b), respectively. XRD analysis shows $\mathrm{FeCo}$ peaks at low temperatures with nominal ferrite peaks. Oxidation occurs gradually until $300{ }^{\circ} \mathrm{C}$ and more rapid oxidation occurs at $350{ }^{\circ} \mathrm{C}$ and above, showing peaks for the spinel ferrite $(\mathrm{Fe}, \mathrm{Co})_{3} \mathrm{O}_{4}$. At temperatures greater than $900{ }^{\circ} \mathrm{C}, \mathrm{FeO}$ peaks are observed and $\mathrm{FeCo}$ peaks are no longer present.

In Fig. 1, it can be seen that magnetite $\left(\mathrm{Fe}_{3} \mathrm{O}_{4}\right)$ is the first oxide to appear with no hematite peaks discernible in the high temperature oxidation experiments; wustite $(\mathrm{FeO})$ is observed at the higher oxidation temperatures tested. This pro- gression of oxidation agrees with the sequence for iron as proposed by Birks et al. ${ }^{10}$ Wustite will only form at temperatures above $570{ }^{\circ} \mathrm{C}$, which confirms its absence at lower temperatures. At lower temperatures, magnetite will form first and will comprise a large fraction of the oxide layer with hematite forming only a thin layer at the interface between the oxide and the air atmosphere. During initial oxidation, the oxygen partial pressure will be high as will the presence of $\mathrm{Fe} / \mathrm{Co}$ at the surface. This will favor a 1:1 ratio of $\mathrm{Fe} / \mathrm{Co}$ to $\mathrm{O}$ in the oxide. Due to the instability of wustite, $\mathrm{Fe}_{3} \mathrm{O}_{4}$ will form. This will occur until the layer is large enough that the $\mathrm{Fe} / \mathrm{Co}$ mobility is low and much of the $\mathrm{Fe} / \mathrm{Co}$ at the surface is tied up in magnetite. At this point, hematite will form.

At higher temperatures, wustite should be seen in greater amounts due to its high defect mobility. This is not seen, however, in the XRD data, except for a few small peaks. This may be due to the technique of oxidation and furnace temperature lag time. After the formation of magnetite, wustite can form; however it will depend on the mobility of large oxygen anions through the magnetite layer in order to react with the $\mathrm{Fe} / \mathrm{Co}$ surface. Since it is difficult to discern $\mathrm{Fe}$ from Co in the XRD data, a more in depth study of the oxide layer will be the subject of future work using Mössbauer, Auger, and x-ray photoelectron spectroscopies to understand

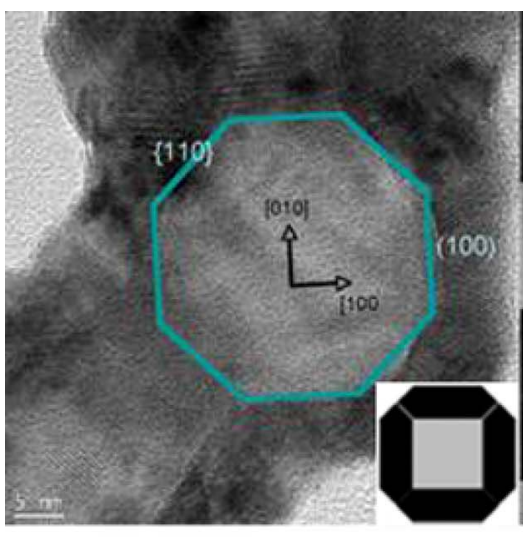

(a)

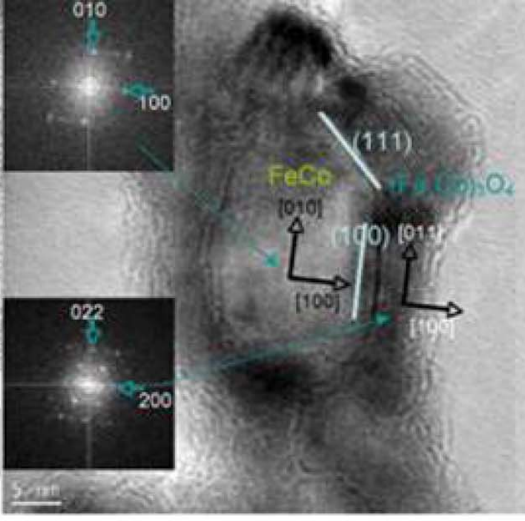

(b)

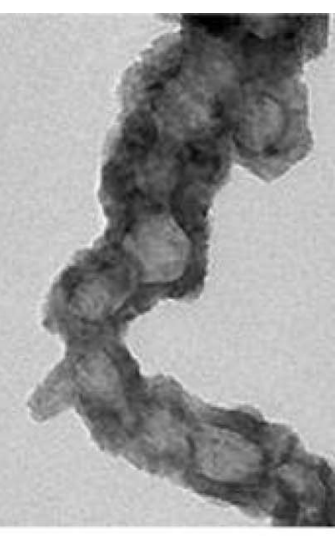

(c)

FIG. 2. (Color online) (a) An FeCo particle (oxidized $24 \mathrm{~h}$ at $350^{\circ} \mathrm{C}$ ) with an octagonal like projection [inset: simulated representation of a (110)-truncated cube using KRYSTALSHAPER ${ }^{\mathrm{TM}}$ software]. (b) An HRTEM of an FeCo particle (oxidized $6 \mathrm{~h}$ at $350{ }^{\circ} \mathrm{C}$ ) showing ORs between it and its oxide and (c) low resolution image of the chaining of particles (oxidized $24 \mathrm{~h}$ at $350^{\circ} \mathrm{C}$ ). 


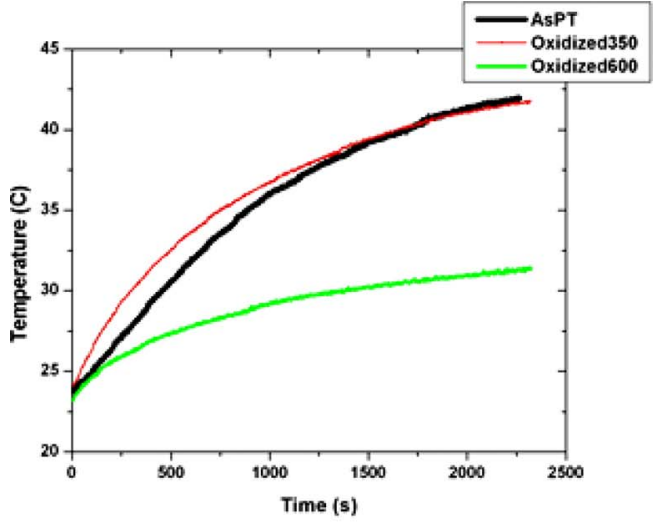

(a)

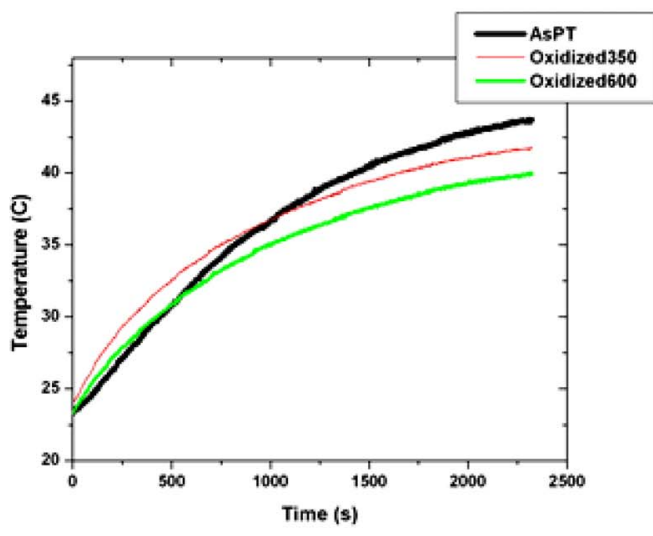

(b)

FIG. 3. (Color online) (a) Heating rates of $10 \mathrm{wt} \%$ FeCo in PEO ferrofluids with powders of varying states of oxidation. While as-PT powders and those oxidized at $350{ }^{\circ} \mathrm{C}$ powders show similar heating rates, powders oxidized at $600{ }^{\circ} \mathrm{C}$ heat significantly slower. (b) Heating curves for ferrofluids with equal magnetization.

the nature of the oxide layer.

The oxidation kinetics were then followed more closely at 350 and $500{ }^{\circ} \mathrm{C}$ for various lengths of time. At $350{ }^{\circ} \mathrm{C}$ significant oxidation occurred after only $15 \mathrm{~min}$ and remained gradual until oxidation increased more rapidly at times longer than $6 \mathrm{~h}$. Oxidation occurred more rapidly at $500{ }^{\circ} \mathrm{C}$ and was nearly fully oxidized after $1.5 \mathrm{~h}$.

A TEM determined nanoparticle log-normal size distribution indicated $\mu=19.7 \mathrm{~nm}$ and $\sigma=8.5 \mathrm{~nm}$. HRTEM showed MNPs to have a thin adherent ferrite shell. The FeCo particle in Fig. 2(a) is seen to have an octagonal-like projection. Such a projected image, from a cubic crystal, could come from a (111)-truncated cube having 14 faces consisting of $\{100\}$ and $\{111\}$ facets or from a (110)-truncated cube having 18 faces consisting of facets of the type $\{110\}$ and $\{100\}$. Since the FeCo particle is either bcc or a derivative ordered structure of bcc (B2) it is likely that the particle has $\{110\}$ facets and not $\{111\}$ facets as the $\{110\}$ planes are low energy in a bcc structure. A schematic of the projection of such an 18 sided particle is shown in the inset of Fig. 2(a).

The FeCo particle shown in Fig. 2(b) reveals one full orientation relationship (OR) between the FeCo particle and its oxide. From the fast Fourier transforms of the high resolution images the ORs can be seen to be

$$
(100)_{\mathrm{FeCo}} \|(100)_{\text {oxide }} \text { and }[010]_{\mathrm{FeCo}} \|[011]_{\text {oxide }} \text {. }
$$

The oxide forms first on the $\{100\}$ facets of the FeCo particle because of a close lattice match between $\{100\}$ of $\mathrm{FeCo}$ and $\{100\}$ of the oxide with $\langle 110\rangle$ oxide $\|\langle 100\rangle \mathrm{FeCo}$. These oxide regions then grow around the particle and meet at $\{110\}$ facets of the $\mathrm{FeCo}$ at a twinlike boundary between them.

The heating rate data of the $10 \mathrm{wt} \%$ ferrofluids in Fig. 3(a) show little difference between the as-PT powder and the $350{ }^{\circ} \mathrm{C}$ oxidized powder, but a significant decrease in heating of the powder oxidized at $600{ }^{\circ} \mathrm{C}$. VSM data of the powders show relatively close saturation magnetization values for as-PT and $350{ }^{\circ} \mathrm{C}$ oxidized powders while the $M_{s}$ of the $600{ }^{\circ} \mathrm{C}$ oxidized powder is nearly half that of the as-PT, which explains the low heating rate due to low magnetization in $(\mathrm{Fe}, \mathrm{Co})_{3} \mathrm{O}_{4}$ compared to FeCo. Peak heating rates are expected at particle sizes smaller than the average diameter of the as-PT FeCo powder. ${ }^{11}$ The particles' oxide grows at the expense of the $\mathrm{FeCo}$, decreasing the size of the core; however the heating rates of the equivalent magnetization ferrofluids were observed to decrease slightly with more oxidation and smaller FeCo core sizes. The apparent effect is small because PT synthesized MNPs are very polydisperse and oxidation has only a small measurable effect on the average particle diameter. Another factor that may contribute to the difference of heating rates is the change in the anisotropy constant of the overall material as the thickness of the oxide increases and $\mathrm{FeCo}$ decreases.

\section{ACKNOWLEDGMENTS}

M.E.M. and D.E.L. acknowledge support of the NSF through Grant No. DMR 0406220 and DMR 0804020 and the Data Storage Systems Center. N.J.J. gratefully acknowledges support from a DOD SMART scholarship. K.N.C. gratefully acknowledges support of the 2007 CMU MRSEC REU program through NSF Grant No. DMR 0520425 and DMR 0648976 and an REU supplement to DMR\#0804020. M.E.M., K.J.M., and K.N.C. gratefully acknowledge helpful discussions with T. Gilbert, P. Chaudhary, and R. Swaminathan.

${ }^{1}$ Z. Turgut, M.-Q. Huang, K. Gallagher, S. A. Majetich, and M. E. McHenry, J. Appl. Phys. 81, 4039 (1997); Z. Turgut, J. H. Scott, S. A. Majetich, and M. E. McHenry, ibid. 83, 6468 (1998).

${ }^{2}$ A. H. Habib, C. L. Ondeck, P. Chaudhary, M. R. Bockstaller, and M. E. McHenry, J. Appl. Phys. 103, 07A307 (2008).

${ }^{3}$ T. W. Gilbert, A. M. Stewart-Akers, and S. F. Badylak, Biomaterials 28, 147 (2007).

${ }^{4}$ K. J. Miller, K. N. Collier, H. B. Soll-Morris, R. Swaminathan, and M. E. McHenry, J. Appl. Phys.(this conference).

${ }^{5}$ R. Swaminathan, M. E. McHenry, P. Poddar, and H. Srikanth, J. Appl. Phys. 97, 10G104 (2005).

${ }^{6}$ Gas atomized powders were provided by Z. Turgut, AFRL-WPAFB.

${ }^{7}$ Z. Turgut, N. T. Nuhfer, H. R. Piehler, and M. E. McHenry, J. Appl. Phys. 85, 4406 (1999).

${ }^{8}$ M. Sorescu, personal communication (1/24/2008).

${ }^{9}$ M. A. Willard, L. K. Kurihara, E. E. Carpenter, S. Calvin, and V. G. Harris, Int. Mater. Rev. 49, 125 (2004).

${ }^{10}$ N. Birks, G. H. Meier, and F. S. Pettit, Introduction to the HighTemperature Oxidation of Metals, 2nd ed. (Cambridge University Press, New York, 2006).

${ }^{11}$ R. E. Rosensweig, J. Magn. Magn. Mater. 252, 370 (2002). 